\title{
A reinvestigation of recruitment to randomised, controlled, multicenter trials: a review of trials funded by two UK funding agencies
}

\author{
Ben G O Sully ${ }^{1}$, Steven A Julious ${ }^{1 *}$ and Jon Nicholl ${ }^{2}$
}

\begin{abstract}
Background: Randomised controlled trials (RCTs) are the gold standard assessment for health technologies. A key aspect of the design of any clinical trial is the target sample size. However, many publicly-funded trials fail to reach their target sample size. This study seeks to assess the current state of recruitment success and grant extensions in trials funded by the Health Technology Assessment (HTA) program and the UK Medical Research Council (MRC).

Methods: Data were gathered from two sources: the National Institute for Health Research (NIHR) HTA Journal Archive and the MRC subset of the International Standard Randomised Controlled Trial Number (ISRCTN) register. A total of 440 trials recruiting between 2002 and 2008 were assessed for eligibility, of which 73 met the inclusion criteria. Where data were unavailable from the reports, members of the trial team were contacted to ensure completeness.

Results: Over half (55\%) of trials recruited their originally specified target sample size, with over three-quarters (78\%) recruiting $80 \%$ of their target. There was no evidence of this improving over the time of the assessment. Nearly half (45\%) of trials received an extension of some kind. Those that did were no more likely to successfully recruit. Trials with $80 \%$ power were less likely to successfully recruit compared to studies with $90 \%$ power.

Conclusions: While recruitment appears to have improved since 1994 to 2002, publicly-funded trials in the UK still struggle to recruit to their target sample size, and both time and financial extensions are often requested. Strategies to cope with such problems should be more widely applied. It is recommended that where possible studies are planned with 90\% power.
\end{abstract}

Keywords: Extension, Health Technology Assessment, Medical Research Council, Power, Recruitment, Sample size

\section{Background}

This study seeks to assess the current state of recruitment success and grant extensions in trials funded by the UK Health Technology Assessment (HTA) program and the UK Medical Research Council (MRC). This work updates a review for the interval 1994 to 2002 by McDonald et al. [1].

When planning a trial, one essential step is the calculation of a sample size that will give the minimum number of participants required to meet the objectives of the study [2].

\footnotetext{
*Correspondence: s.a.julious@sheffield.ac.uk

${ }^{1}$ Medical Statistics Group, School of Health and Related Research, University of Sheffield, 30 Regent Court, Regent Street, Sheffield S1 4DA, UK Full list of author information is available at the end of the article
}

Having a good estimate of the sample size is important, as studies that are either too small or too large may be judged unethical [3]. For example, a study that is too large could have met the objectives of the trial before the actual study end had been reached, meaning that some patients may have unnecessarily entered into the trial and been randomised to a therapy that can be proven to be suboptimal. Conversely, a trial that is too small may have little chance of meeting the study objectives, and patients may be entering a trial for no tangible benefit.

Poor recruitment is acknowledged as an important shortcoming of many randomised controlled trials (RCTs), which can prevent a study from reaching its target sample size $[1,4,5]$. Of trials published in the British Medical

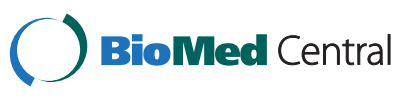


Journal (BMI) and the Lancet between 2000 and 2001, $51 \%$ of multicentered trials reported difficulties in recruitment [6], while a 2006 review of publicly-funded multicenter trials found that less than a third of all studies achieved their recruitment target and half of all studies received an extension [1].

The consequences of poor recruitment are varied. If the target sample size is not met then the chances of seeing a statistically significant result when there is a true difference between treatments will be reduced, therefore decreasing the likelihood of finding evidence of an effect for a particular health technology.

Poor recruitment also has a negative impact on a trial's costs: if an extension is required to obtain the target sample size, the trial's budget will be increased.

While the issue is not new, there is little quantitative research on the extent of the problem. This review aims to update research funded by the UK National Health Service (NHS) R\&D National Methodology Programme and the UK MRC in 2006, which looked at recruitment to publicly-funded multicenter trials between 1994 and 2002 [1]. In this study, we update this review to look at studies undertaken between 2002 and 2008 .

\section{Methods}

Trial identification

We looked at 73 trials funded by the HTA and the UK MRC. Data were collected from the online databases held by the bodies: the MRC subset of the Current Controlled Trials metaregister (http://www.controlled-trials. $\mathrm{com} / \mathrm{mrct} /$ ), and the HTA archive of published articles (http://www.hta.ac.uk/project/htapubs.asp). Inclusion and exclusion criteria were chosen to match the previous study [1]. Trials were eligible if: (1) they were multicenter (multicenter trials are commonly reported to recruit more slowly than expected [7]), (2) recruitment started on or after 1 January 2002, (3) recruitment was originally planned to close on or before 31 December 2008 (trials that were awarded an extension beyond 31 December 2008 were included if they had closed to recruitment when data were extracted), and (4) they were not a cluster randomised trial (these were excluded because recruitment issues differ).

These criteria were chosen to be consistent with McDonald et al. [1] to ensure comparability. Note that there is no overlap between these two pieces of research: the previous study required trials to have finished recruiting by 1 January 2002, and ours

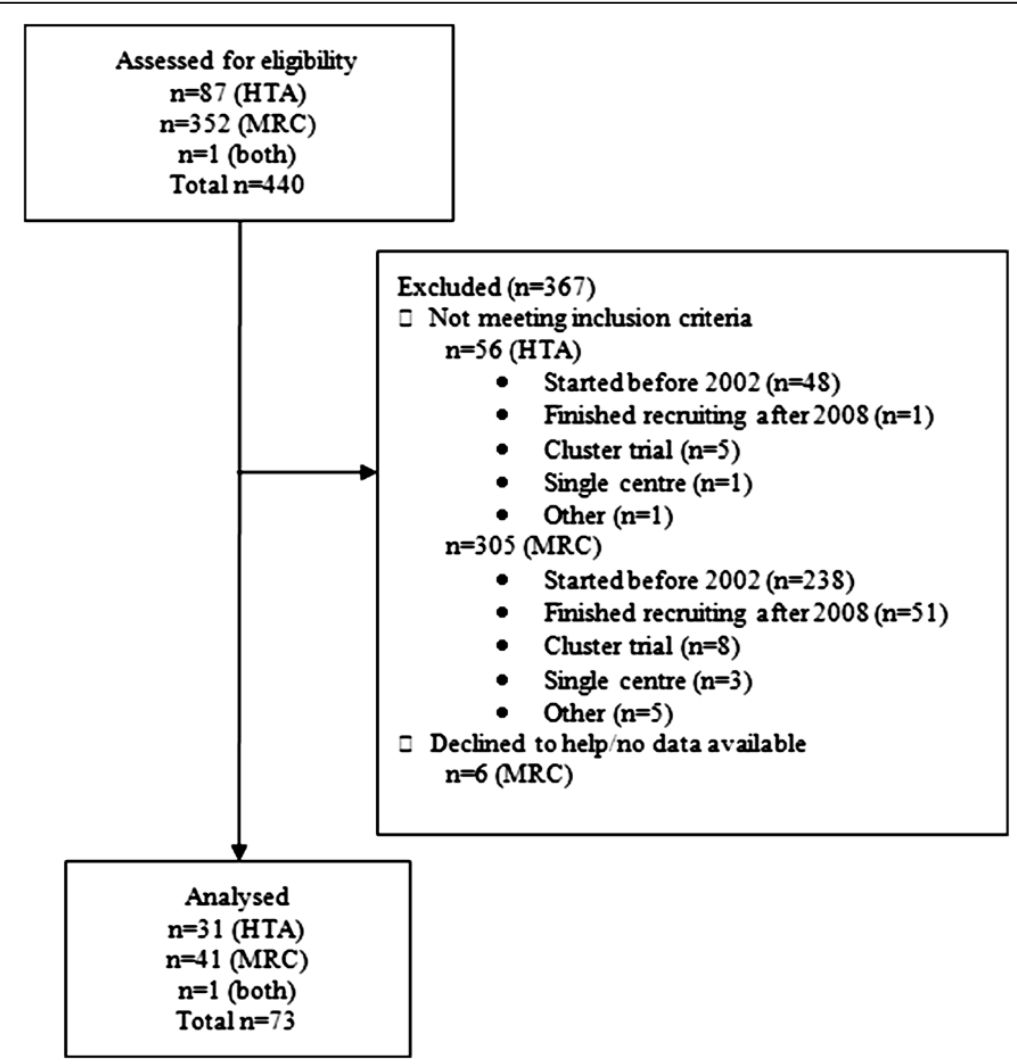

Figure 1 Flow diagram for the study. 
requires trials to have started recruiting on or after this period.

\section{Data extraction}

The International Standard Randomised Controlled Trial Number (ISRCTN) was captured for each trial. For HTA-funded trials, the original HTA publication was used. MRC-funded trials were investigated on a case-by -case basis, where possible using the original study protocol, clinical report, or trial website found by using the ISRCTN. For trials where no information could be found, the principal investigator or trial manager was contacted.

While the reporting of trials was largely of a good standard, there were limits on the trial details published. Occasionally, therefore, we were not able to gather information on certain specifics, denoted by the 'Missing' values in tables.

Trial recruitment was classed as a 'success' if the original or revised recruitment target was met, or if the trial was stopped early due to an interim analysis. Trials that were terminated (for example, due to slow recruitment) were classed as failing to recruit.

Where appropriate, $\chi^{2}$ tests and $\chi^{2}$ tests for trend were used to test for differences between the two study periods (1994 to 2002 and 2002 to 2008), between trials with and without a clinical trials unit (CTU), and between trials that successfully recruited and those that did not. Categories with insufficient data and categories corresponding to missing data were excluded from these tests. Data were collected and analyzed in SPSS version 19 (SPSS Inc., Chicago, IL, USA).

\section{Power calculations}

In addition to capturing recruitment, the planned power for each trial was also captured. Using this along with the target and achieved recruitment allows the true achieved power to be calculated for each trial. This will be performed by simply rearranging and applying the appropriate sample size formula using the proportion of the target sample size that was actually recruited, and does not require using any other trial results. The process for each study is as follows:

1 . Assume a planned type I error $\alpha$ of 0.05 , and use the planned sample size $n$ and the planned power $1-\beta$ to determine the approximate standardised effect size $\delta$ of the study using the formula:

$$
\delta^{2}=2\left(Z_{1-\alpha / 2}+Z_{1-\beta}\right)
$$

2. Calculate the proportion $\pi$ of the planned sample size $n$ actually recruited to the study
Table 1 Characteristics of trials

\begin{tabular}{|c|c|c|c|c|}
\hline \multirow[t]{2}{*}{ Characteristic } & \multicolumn{2}{|c|}{1994 to 2002} & \multicolumn{2}{|c|}{2002 to 2008} \\
\hline & $\mathrm{N}$ & n (\%) & $\mathrm{N}$ & n (\%) \\
\hline What type of trial design was used? & 122 & & 73 & \\
\hline Parallel & & $113(93)$ & & $66(90)$ \\
\hline Factorial & & $6(5)$ & & $4(5)$ \\
\hline $\begin{array}{l}\text { Partially randomised patient } \\
\text { preference }\end{array}$ & & $3(2)$ & & $3(4)$ \\
\hline $\begin{array}{l}\text { How many arms were there } \\
\text { in the trial? }\end{array}$ & 122 & & 73 & \\
\hline Two & & $94(77)$ & & $53(73)$ \\
\hline Three & & $18(15)$ & & $14(19)$ \\
\hline More than three & & $10(8)$ & & $6(8)$ \\
\hline $\begin{array}{l}\text { What clinical area was the } \\
\text { trial investigating? }\end{array}$ & 122 & & 73 & \\
\hline Cancer & & $25(20)$ & & $4(5)$ \\
\hline $\begin{array}{l}\text { Mental health (including } \\
\text { neurosciences/psychiatry/ } \\
\text { psychology) }\end{array}$ & & $21(17)$ & & $13(18)$ \\
\hline $\begin{array}{l}\text { Orthopedics/rheumatology } \\
\text { (including back pain) }\end{array}$ & & $21(17)$ & & $1(1)$ \\
\hline Obstetrics and gynecology & & $9(7)$ & & $2(3)$ \\
\hline Primary care & & $8(7)$ & & $13(18)$ \\
\hline Cardiology & & $5(4)$ & & $4(5)$ \\
\hline Gastroenterology & & $5(4)$ & & $0(0)$ \\
\hline Incontinence/urology & & $5(4)$ & & $3(4)$ \\
\hline HIV/AIDS & & $5(4)$ & & $4(5)$ \\
\hline Other & & $18(15)$ & & $29(40)$ \\
\hline $\begin{array}{l}\text { In what setting did the trial } \\
\text { take place? }\end{array}$ & 122 & & 73 & \\
\hline Hospital & & $64(53)$ & & $29(40)$ \\
\hline General practice & & $26(21)$ & & $12(16)$ \\
\hline Mixed & & $16(13)$ & & $17(23)$ \\
\hline Community & & $7(6)$ & & $15(21)$ \\
\hline Missing & & $9(7)$ & & $0(0)$ \\
\hline $\begin{array}{l}\text { Were there any recruiting } \\
\text { centers outside the UK? }\end{array}$ & 114 & & 73 & \\
\hline No & & $88(77)$ & & $62(85)$ \\
\hline Yes & & $25(22)$ & & $11(15)$ \\
\hline Missing & & $1(1)$ & & $0(0)$ \\
\hline Was a clinical trials unit involved? & 114 & & 73 & \\
\hline Yes & & $89(78)$ & & $31(42)$ \\
\hline No & & $25(22)$ & & $40(55)$ \\
\hline Missing & & $0(0)$ & & $2(3)$ \\
\hline Which body funded the trial? & 122 & & 73 & \\
\hline UK Medical Research Council (MRC) & & $73(64)$ & & $41(56)$ \\
\hline $\begin{array}{l}\text { UK Health Technology } \\
\text { Assessment (HTA) }\end{array}$ & & $41(36)$ & & $31(43)$ \\
\hline Both & & $0(0)$ & & $1(100)$ \\
\hline
\end{tabular}


3. Calculate the achieved power of a study with parameters $\alpha, \delta^{2}$ and $\sigma^{2}$ and sample size $\pi n$ using the formula:

$$
(1-\beta) \text { achieved }=\Phi\left[\sqrt{\frac{\pi n \delta^{2}}{2}}-Z_{1-\alpha / 2}\right]
$$

\section{Results}

The databases contained 73 trials fulfilling the inclusion criteria. Figure 1 shows the flow of trials through the review; 31 (43\%) were funded by the HTA, 41 (56\%) by the MRC, and $1(1 \%)$ by both bodies.

\section{Trial characteristics}

Table 1 summarises the individual characteristics of the trials. The majority were simple parallel group trials (66 (90\%)) with the remainder being factorial designs $(4(5 \%))$ or partially randomised patient preference designs $(3(4 \%))$. Approximately three-quarters of trials had 2 arms (53, (73\%)).

The most common clinical areas for the trials were in mental health $(13(18 \%))$ and primary care (13 (18\%)), which is a slight change from previous findings [1] where cancer and orthopedics/rheumatology trials were the most prevalent. There was a large variety in the clinical area being investigated, reflected by the large number of clinical areas labeled as 'Other'. We also found a slight decrease in the number of hospital-based trials (40\% vs 53\% reported previously [1]) with more community-based trials (21\%, up from $6 \%$ ).

\section{Recruitment}

Target recruitments ranged from 56 to 8,000 participants, whereas actual recruitment ranged from 44 to 8,164 participants. Information on the distribution of both target and achieved sample sizes of trials is shown in Table 2.

Table 3 describes the success of trial recruitment in comparison to their original targets. The target was only met in $40(55 \%)$ of trials; meanwhile, $17(23 \%)$ trials recruited to $80 \%$ but less than $100 \%$ of their target. This is an improvement compared to 1994 to 2002, when only $31 \%$ of trials successfully recruited their target $(P$ value associated with this difference $=0.002)$. We also found that fewer trials revised their sample size than in 1994 to 2002 , with only $19 \%$ doing so (down from $34 \% ; P=0.036)$. In five $(36 \%)$ of these, the target was revised upwards; the remaining nine $(64 \%)$ of

Table 2 Numerical characteristics of trials

\begin{tabular}{|c|c|c|c|c|c|}
\hline Characteristic & Valid n (\%) & $\begin{array}{l}\text { Recruited } \\
\text { successfully (\%) }\end{array}$ & Mean (SD) & Median & $\begin{array}{l}\text { Minimum } \\
\text { to maximum }\end{array}$ \\
\hline \multicolumn{6}{|l|}{ No. of centers: } \\
\hline Total & $60(82)$ & $34(57)$ & $38.6(47.9)$ & 15.5 & 2 to 205 \\
\hline 2 to 5 & $16(27)$ & $9(56)$ & $3.4(1.3)$ & 3.5 & \\
\hline 6 to 10 & $9(15)$ & $5(56)$ & $7.6(1.4)$ & 8.0 & \\
\hline 11 to 20 & $7(12)$ & $4(57)$ & $14.3(2.7)$ & 13.0 & \\
\hline 21 to 50 & $11(18)$ & $6(55)$ & $33.2(8.4)$ & 34.0 & \\
\hline 51 to 100 & $9(15)$ & $4(44)$ & $68(12.6)$ & 68.0 & \\
\hline $101+$ & $8(13)$ & $6(75)$ & 139.5 (39.5) & 119.0 & \\
\hline \multicolumn{6}{|c|}{ Target recruitment: } \\
\hline Total & 73 & $40(55)$ & $706.3(1,098.0)$ & 388.0 & 56 to 8,000 \\
\hline 1 to 100 & $6(8)$ & $4(67)$ & $77.8(14.1)$ & 78.0 & \\
\hline 101 to 200 & $11(15)$ & $6(55)$ & $156.8(30.4)$ & 150.0 & \\
\hline 201 to 400 & $24(33)$ & $15(63)$ & 315.9 (56.6) & 305.0 & \\
\hline 401 to 1,000 & $22(30)$ & $10(46)$ & $637.5(168.5)$ & 595.0 & \\
\hline $1,001+$ & $10(14)$ & $5(50)$ & $2,776(1,938.7)$ & $2,250.0$ & \\
\hline \multicolumn{6}{|c|}{ Final recruitment } \\
\hline Total & 73 & $40(55)$ & $623.7(1,117.3)$ & 325.0 & 44 to 8,164 \\
\hline 1 to 100 & $7(10)$ & $1(14)$ & $80.3(36.8)$ & 58.0 & \\
\hline 101 to 200 & $14(19)$ & $8(57)$ & $160.4(60.1)$ & 151.0 & \\
\hline 201 to 400 & $24(33)$ & $14(58)$ & 295.8 (75.6) & 284.0 & \\
\hline 401 to 1,000 & $20(27)$ & $12(60)$ & 519.2 (313.9) & 538.5 & \\
\hline $1,001+$ & $8(11)$ & $5(63)$ & $2,476.3(2,269.6)$ & $2,478.5$ & \\
\hline
\end{tabular}


Table 3 Recruitment in trials

\begin{tabular}{|c|c|c|c|c|c|c|c|c|c|c|}
\hline & \multirow{2}{*}{\multicolumn{2}{|c|}{$\frac{1994 \text { to } 2002}{\text { Total }}$}} & \multicolumn{8}{|c|}{2002 to 2008} \\
\hline & & & \multicolumn{2}{|c|}{ Total } & \multirow{2}{*}{$\begin{array}{l}P \\
\text { value }\end{array}$} & \multicolumn{2}{|c|}{ With CTU } & \multicolumn{2}{|c|}{ Without CTU } & \multirow{2}{*}{$\begin{array}{l}P \\
\text { value }\end{array}$} \\
\hline & $\mathrm{N}$ & n (\%) & $\mathrm{N}$ & n (\%) & & $\mathrm{N}$ & n (\%) & $\mathrm{N}$ & n (\%) & \\
\hline Was recruitment a success? & 122 & & 73 & & $0.002^{a}$ & 31 & & 40 & & $0.235^{\mathrm{a}}$ \\
\hline Yes & & $38(31)$ & & $40(55)$ & & & $20(65)$ & & $19(48)$ & \\
\hline No & & $84(69)$ & & $33(45)$ & & & $11(36)$ & & $21(53)$ & \\
\hline Was the recruitment target revised? & 122 & & 73 & & $0.036^{\mathrm{a}}$ & 31 & & 40 & & $0.1183^{\mathrm{a}}$ \\
\hline Yes & & $42(34)$ & & $14(19)$ & & & $3(10)$ & & $11(28)$ & \\
\hline No & & $76(62)$ & & $56(77)$ & & & $27(87)$ & & $28(70)$ & \\
\hline Missing & & $4(3)$ & & $3(4)$ & & & $1(3)$ & & $1(3)$ & \\
\hline \multicolumn{11}{|l|}{ Final recruitment figure } \\
\hline Original target: & 122 & & 73 & & $<0.001^{\mathrm{b}}$ & 31 & & 40 & & $<0.001^{\mathrm{b}}$ \\
\hline$\geq 100 \%$ & & $38(31)$ & & $40(55)$ & & & $20(65)$ & & $19(48)$ & \\
\hline$\geq 80 \%$ but $<100 \%$ & & $29(24)$ & & $17(23)$ & & & $8(26)$ & & $9(23)$ & \\
\hline$<80 \%$ & & $55(45)$ & & $16(22)$ & & & $3(10)$ & & $12(30)$ & \\
\hline Revised target: & 42 & & 14 & & $0.021^{b}$ & 3 & & 11 & & $N / A^{b}$ \\
\hline$\geq 100 \%$ & & $19(45)$ & & $10(71)$ & & & $2(67)$ & & $8(73)$ & \\
\hline$\geq 80 \%$ but $<100 \%$ & & $15(36)$ & & $3(21)$ & & & $0(0)$ & & $3(27)$ & \\
\hline$<80 \%$ & & $8(19)$ & & $1(7)$ & & & $1(33)$ & & $0(0)$ & \\
\hline
\end{tabular}

${ }^{\mathrm{a}} P$ values calculated using $X^{2}$ tests, excluding missing categories.

${ }^{\mathrm{b}} P$ values calculated using $X{ }^{2}$ tests for trend; in the final case counts were too small to perform tests.

CTU, clinical trials unit; N/A, not applicable.

trials revised the target downwards. The new target was met in the majority $(10(71 \%))$ of trials in which it was revised, another improvement since the previous study period (19 (45\%)).

The planned size of a trial appears to have a slight negative effect on the success of recruitment, but the effect is less pronounced than may be imagined: trials requiring over 1,000 participants recruit successfully $50 \%$ of the time, compared to trials requiring 100 to 200 participants $55 \%$ of the time, and 1 to 100 people $67 \%$ of the time. Some categories also contained few studies, so may not be representative of the success of all trials.

The impact of clinical trials units (CTUs) on trials is positive. A total of $31(42 \%)$ trials had CTUs involved, down from $78 \%$ in 1994 to 2002 [3]. Of these 31, 20 (65\%) recruited successfully, while trials without CTUs successfully recruited only $48 \%$ of the time (19 trials).

Table 4 shows how other trial characteristics affected the recruitment of trials. MRC-funded trials appear to recruit successfully more often than HTA-funded trials (25 (61\%) compared to 14 (45\%)) although the difference is not statistically significant $(P=0.270)$. The clinical area of a trial, however, does seem to influence recruitment success: eight (62\%) mental health trials recruited successfully compared to only three (23\%) primary care trials. However, the sample size for the majority of these categories is too small to perform meaningful statistical tests. Trials with $\leq 16$ centers (the median number of centers) did not recruit any more successfully than those with $>16$ centers ( $57 \%$ vs $57 \%)$.

Three $(4 \%)$ trials had unscheduled trial terminations. One was halted for ethical reasons discovered during the trial (another study showing negative results was published during the trial and the intervention was deemed to be ineffective; at this point the target sample size had not been reached) and two due to slow recruitment. These were all coded as being unsuccessful in recruitment.

\section{Extensions}

Table 5 summarises the number of extensions given to trials. Just over half (39 (53\%)) of trials had no extension. Those that did largely received time $(22(30 \%))$ or time and grant $(10(14 \%))$ extensions. Only a single (1\%) trial received a grant extension alone. These data were missing for one (1\%) trial. A total of $20(64 \%)$ trials funded by the HTA required an extension of some kind, compared to only $12(29 \%)$ of trials funded by the MRC, a statistically significant difference $(P<0.01)$.

Not all studies reported whether they received an extension. Where an extension was not reported we contacted the trial's chief investigator as identified through the ISRCTN database; this was necessary for eight trials, and in one case we did not get a reply. This was coded as missing in the database.

These data are simplified in Figure 2, where all extensions have been grouped together. In all, 33 (45\%) trials 
Table 4 How factors affected recruitment

\begin{tabular}{|c|c|c|c|}
\hline \multirow[t]{2}{*}{ Factor } & \multicolumn{3}{|c|}{ Was recruitment a success? } \\
\hline & Yes, n (\%) & No, $n(\%)$ & $P$ value \\
\hline Funding body: & & & $0.182^{\mathrm{a}, \mathrm{b}}$ \\
\hline $\begin{array}{l}\text { UK Medical Research } \\
\text { Council (MRC) }\end{array}$ & $25(61)$ & $16(39)$ & \\
\hline $\begin{array}{l}\text { UK Health Technology } \\
\text { Assessment (HTA) }\end{array}$ & $14(45)$ & $17(55)$ & \\
\hline Both & $1(100)$ & $0(0)$ & \\
\hline Setting: & & & $0.970^{\mathrm{a}}$ \\
\hline Hospital & $16(55)$ & $13(45)$ & \\
\hline General practice & $6(50)$ & $6(50)$ & \\
\hline Mixed & $10(59)$ & $7(41)$ & \\
\hline Community & $8(53)$ & $7(47)$ & \\
\hline \multicolumn{4}{|l|}{ Clinical area: } \\
\hline Cancer & $3(75)$ & $1(25)$ & \\
\hline $\begin{array}{l}\text { Mental health (including } \\
\text { neurosciences/psychiatry/ } \\
\text { psychology) }\end{array}$ & $8(62)$ & $5(39)$ & \\
\hline $\begin{array}{l}\text { Orthopedics/rheumatology } \\
\text { (including back pain) }\end{array}$ & $1(100)$ & $0(0)$ & \\
\hline Obstetrics and gynecology & $1(50)$ & $1(50)$ & \\
\hline Primary care & $3(23)$ & $10(77)$ & \\
\hline Cardiology & $1(25)$ & $3(75)$ & \\
\hline Incontinence/urology & $3(100)$ & $0(0)$ & \\
\hline HIV/AIDS & $3(75)$ & $1(25)$ & \\
\hline Other & $17(59)$ & $12(41)$ & \\
\hline \multicolumn{4}{|l|}{ Number of centers: } \\
\hline$\leq 16$ & $17(57)$ & $13(43)$ & \\
\hline$>16$ & $17(57)$ & $13(43)$ & \\
\hline Missing & 6 & 7 & \\
\hline
\end{tabular}

${ }^{\mathrm{a}} P$ values calculated using $X^{2}$ tests without continuity corrections.

${ }^{b}$ Both' column excluded from $X^{2}$ test due to low counts.

received an extension and of these 18 (55\%) recruited to their target. A total of 39 (53\%) trials did not receive an extension; of these, 21 (54\%) recruited successfully. Hence, trials receiving extensions are equally likely to recruit to $100 \%$ of their target sample size as those not receiving extensions; however, they are more likely to recruit at least $80 \%$ of their target (see Figure 2).

\section{Power}

Results from power calculations are summarised in Table 6 and Figure 3. Only three trials prespecified their power as any number other than $80 \%$ or $90 \%$; one planned $83 \%$, one $85 \%$, and one $95 \%$ power. Of studies that planned for $90 \%$ power, $89 \%$ (26) managed to recruit a minimum of $80 \%$ of their initially planned sample size, compared with only $72 \%$ (28) of trials planned with $80 \%$ power.

\section{Discussion}

This review has found improved results compared to the 2006 report by McDonald et al. [1]. Slow or inadequate recruitment to publicly-funded multicenter RCTs is still a common problem however, with a large proportion requiring extensions. The previous report looked at trials recruiting between 1994 and 2002; we updated this to look at trials recruiting between 2002 and 2008. We found slightly fewer eligible trials (73, compared to 114; 10.4 per year compared to 12.7 per year).

Over half of trials recruited to $100 \%$ of their original target, up from around one-third in the previous 8 years. Additionally the proportion of trials failing to recruit $80 \%$ of their target in 2002 to 2008 was around onefifth; down from $45 \%$ in 1994 to 2002 . This trend is promising and could reflect the large amount of work aimed at increasing recruitment to clinical trials [8], but the proportion of trials recruiting their target is still considerably less than desirable. More research into both the reasons behind poor recruitment and methods of improving it is needed to help increase this over the next decade.

We found that studies performing sample size calculations based on $90 \%$ power were much more likely to reach at least the minimum acceptable level of $80 \%$ power than those planned based on $80 \%$ power, as shown in Figure 3. Over half of studies with a planned power of between $80 \%$ and $90 \%$ finished with inadequate

Table 5 Extensions to trials

\begin{tabular}{|c|c|c|c|c|c|c|c|c|c|c|c|c|}
\hline \multirow{3}{*}{$\begin{array}{l}\text { Was an extension } \\
\text { granted and if so, } \\
\text { what type? }\end{array}$} & \multirow{2}{*}{\multicolumn{2}{|c|}{$\frac{1994 \text { to } 2002}{\text { Total }}$}} & \multicolumn{10}{|c|}{2002 to 2008} \\
\hline & & & \multicolumn{2}{|c|}{ Total } & \multicolumn{2}{|c|}{ With CTU } & \multicolumn{2}{|c|}{ Without CTU } & \multicolumn{2}{|c|}{ HTA } & \multicolumn{2}{|c|}{ MRC } \\
\hline & $\mathrm{N}$ & n (\%) & $\bar{N}$ & n (\%) & $\mathrm{N}$ & n (\%) & $\mathrm{N}$ & n (\%) & $\mathrm{N}$ & n (\%) & $\mathrm{N}$ & n (\%) \\
\hline & 122 & & 73 & & 31 & & 40 & & 31 & & 41 & \\
\hline No & & $57(47)$ & & $39(53)$ & & $13(42)$ & & $25(63)$ & & $11(36)$ & & 28 \\
\hline Time extension & & $15(12)$ & & $22(30)$ & & $14(45)$ & & $7(18)$ & & $17(55)$ & & $4(10)$ \\
\hline Grant extension & & $8(7)$ & & $1(1)$ & & $0(0)$ & & $1(3)$ & & $0(0)$ & & $1(2)$ \\
\hline Time + grant extension & & $42(34)$ & & $10(14)$ & & $4(13)$ & & $6(15)$ & & $3(10)$ & & $7(17)$ \\
\hline Missing & & $0(0)$ & & $1(1)$ & & $0(0)$ & & $1(3)$ & & $0(0)$ & & $1(2)$ \\
\hline
\end{tabular}

CTU, clinical trials units; HTA, Health Technology Assessment; MRC, Medical Research Council. 


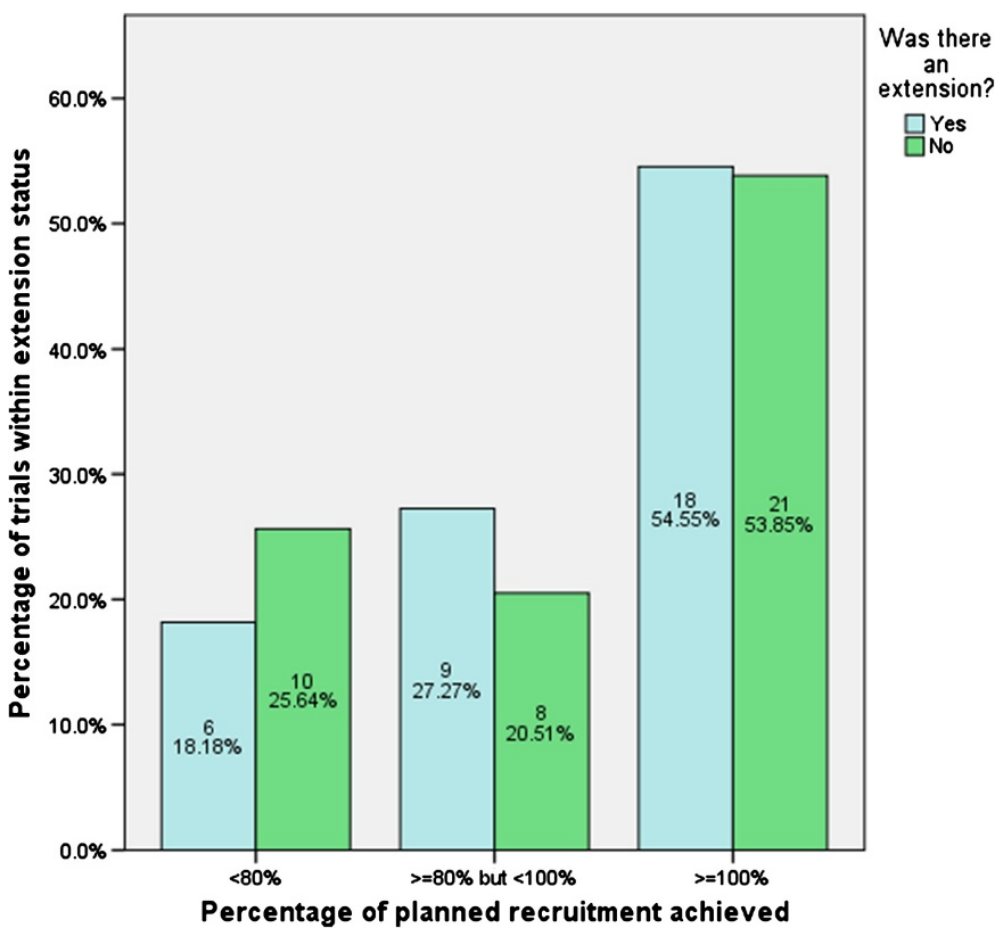

Figure 2 Recruitment by extension status.

power. In addition, studies that plan for $90 \%$ power are more likely to complete with at least $80 \%$ power than those that plan for $80 \%$. Our advice therefore is to design a trial with as high a power as possible: if the study underrecruits there is the opportunity to reduce the power to at least $80 \%$ power.

Extensions have become less commonplace, but are still granted in a large proportion of trials. Figure 2 shows that trials receiving an extension are no more likely to recruit $100 \%$ of their target than those not receiving one; they are however more likely to recruit between $80 \%$ and $100 \%$ of their target. That is not to say that extensions have no use, as extensions more than likely facilitated the recruitment achieved.

The proportion of publicly-funded trials using CTUs has decreased compared to pre-2002. However, the HTA now requires evidence of CTU involvement when funding trials, which could have caused this proportion to have increased since 2008. CTU involvement did not reduce the prevalence of extension requests, but was associated with improved recruitment to trials.

Trials with CTUs appear to obtain extensions more often than trials without (58\% compared to $36 \%$ ). This could be because slow recruitment in CTU studies is due to factors beyond the control of the trial team, or it could be because trials involving CTUs are reported more thoroughly and are less likely to omit the presence of an extension. It appears that the HTA are more willing to provide extensions than the MRC (64\% of HTA trials were given an extension of some kind, compared to $32 \%$ of MRC trials), perhaps due to the type of trials they tend to fund.

There have been many reviews of methods to improve recruitment to trials, particularly in the last 10 years. Watson and Torgerson [5] undertook a systematic review of RCT trialing methods, with the aim of identifying effective strategies. They found that there were very few such trials, but specific strategies to help recruitment included not blinding, educating clinicians, using culturally specific designs and incentives for participants.

Table 6 Planned and true power of trials

\begin{tabular}{|c|c|c|c|c|c|}
\hline & \multicolumn{5}{|c|}{ Planned power } \\
\hline & \multicolumn{2}{|c|}{$80 \%$ to $89 \%$} & \multicolumn{2}{|c|}{$90 \%+$} & \multirow{2}{*}{$\begin{array}{l}\text { Missing } \\
\mathrm{N}\end{array}$} \\
\hline & $\mathrm{N}$ & n (\%) & $\mathrm{N}$ & n (\%) & \\
\hline True power & 39 & & 28 & & 6 \\
\hline $90 \%+$ & & $2(7)$ & & $10(53)$ & \\
\hline $80 \%$ to $89 \%$ & & $12(43)$ & & $4(21)$ & \\
\hline$<80 \%$ & & $14(50)$ & & $5(26)$ & \\
\hline Missing & & 11 & & 9 & \\
\hline Final recruitment & 39 & & 28 & & 6 \\
\hline$\geq 100 \%$ & & $22(56)$ & & $16(57)$ & \\
\hline$\geq 80 \%$ but less than $100 \%$ & & $6(15)$ & & $9(32)$ & \\
\hline$<80 \%$ & & $11(28)$ & & $3(11)$ & \\
\hline
\end{tabular}




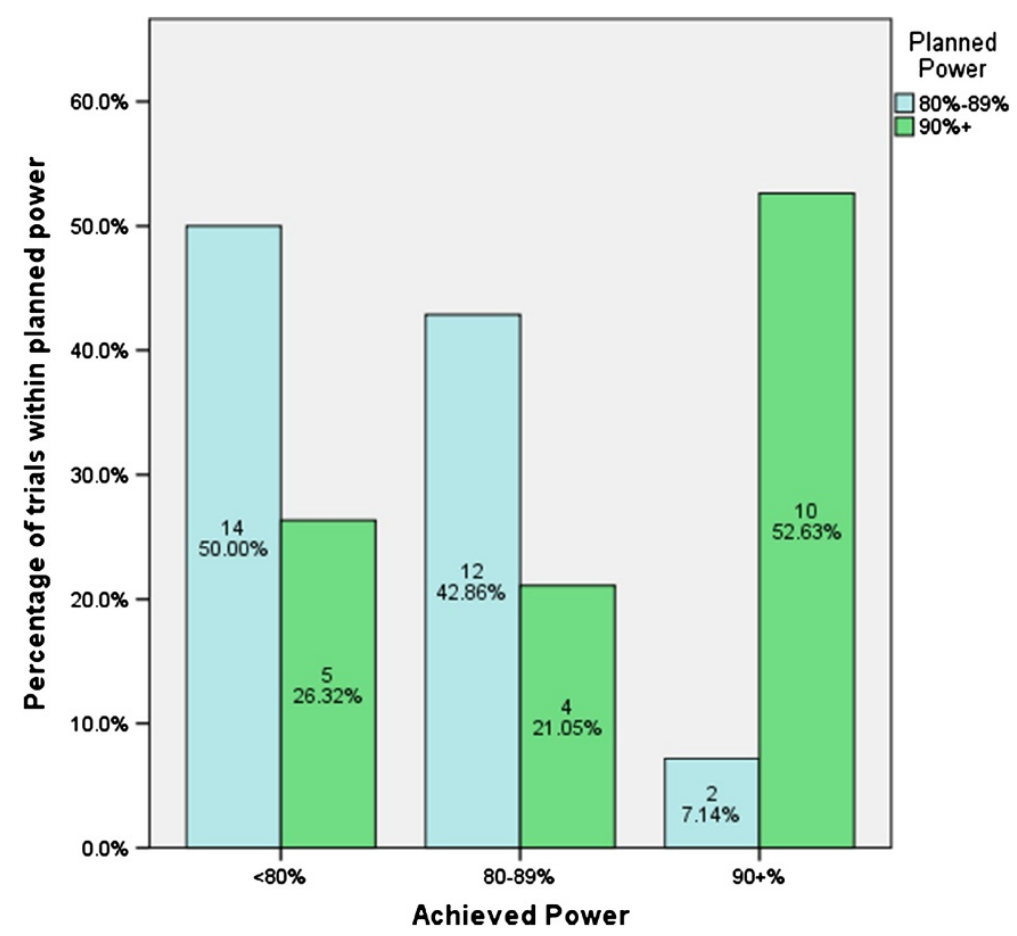

Figure 3 Achieved power of studies by planned power (missing data omitted).

With poor recruitment having such prevalence in current RCTs, more advanced statistical methods should be considered in trial planning and analysis. One particularly attractive and increasingly popular strategy is the use of adaptive designs. Such designs provide opportunities to determine the progress of trials, allowing for reassessment of the assumptions in made in the design of a trial as well as to make an assessment of efficacy and futility. They have the potential to save both time and money [9].

One strength of this investigation is its adherence to the methods undertaken by McDonald et al. [1] in their previous study, which allows for a comparison of the results. However, a limitation of this study is the quality of data. All data were retrieved from online reports of HTA-funded and MRC-funded trials, and as such was not always complete. For example, not all studies reported where they had received an extension. It should be noted though that recruitment rates are specified in the Consolidated Standards of Reporting Trials (CONSORT) statement as being required [10], which facilitated extraction of these data.

In undertaking this study we found two studies that were halted due to a significant finding of efficacy in a planned interim analysis by their data monitoring committee, which were subsequently coded as a successful recruitment. As noted in an earlier section there were also two trials that stopped early due to slow recruitment, and another due to ethical reasons; all three of these were coded as a failure to recruit. However, it is quite possible that the studies halted due to efficacy were still under their recruitment target; similarly that the study stopped due to ethical reasons was recruiting to their target. These trials highlight a difficulty of this research where limited information was available on trials, requiring some discretion on the authors' part.

\section{Conclusions}

This study was performed as an update to the 2006 review by McDonald et al. [1]. We found that although recruitment rates have improved since 1994 to 2002 they are still low, with only around half recruiting to their target. Additionally extensions are still widely requested (and granted), with almost one-third of trials receiving an extension of some kind (down from around half in 1994 to 2002). Trials that fail to reach recruitment targets are less likely to answer their objectives and so could have their ethics questioned.

There is clearly room for research on both ways of improving recruitment, and ways of monitoring and managing low recruitment. Involving a CTU in a trial appears to play a role in increasing recruitment to trials. We would recommend that adaptive designs that enable reassessment of the trial design assumptions are more commonly undertaken in public-funded trials.

Trials designed with $80 \%$ power are over twice as likely not to recruit at least $80 \%$ of their target sample size as those designed with 90\%; indeed, planning a trial with $80 \%$ power could be seen as a marker for a study that may fail to recruit. While the commonly used powers of 
$80 \%$ and $90 \%$ are arbitrary, we recommend that where possible trials are designed with higher power; this way, trials can consider sacrificing some power if recruitment is not as successful as expected.

\section{Abbreviations}

CONSORT: Consolidated Standards of Reporting Trials; CTU: clinical trials unit: HTA: Health Technology Assessment; ISRCTN: International Standard Randomised Controlled Trial Number; MRC: Medical Research Council; NHS: National Health Service; NIHR: National Institute for Health Research; RCT: Randomised Controlled Trial..

\section{Competing interests}

The authors declare that they have no competing interests.

\section{Authors' contributions}

BS carried out the data extraction, analysis and report writing. SAJ conceived of the study, assisted with interpretation of results and reporting. JN assisted in analysis, interpretation and reporting. All authors approved the final draft.

\section{Acknowledgements}

We would like to thank the NIHR for providing funding for this research, through the NIHR Research Methods Fellowship. We would also like to thank all trial managers and principal investigators who cooperated and aided in our investigation, and the referees for their comments and suggestions which helped greatly improve the quality of the research. The views expressed are those of the authors.

\section{Author details}

${ }^{1}$ Medical Statistics Group, School of Health and Related Research, University of Sheffield, 30 Regent Court, Regent Street, Sheffield S1 4DA, UK. ${ }^{2}$ School of Health and Related Research, University of Sheffield, 30 Regent Court, Regent Street, Sheffield S1 4DA, UK.

Received: 23 July 2012 Accepted: 14 May 2013

Published: 9 June 2013

\section{References}

1. McDonald AM, Knight RC, Campbell MK, Entwistle VA, Grant AM, Cook JA, Elbourne DR, Francis D, Garcia J, Roberts I, Snowdon C: What influences recruitment to randomised controlled trials? A review of trials funded by two UK funding agencies. Trials 2006, 7:9.

2. Julious SA: Sample Sizes for Clinical Trials. Boca Raton, FL: CRC Press; 2010

3. Altman DG: Medicine and mathematics - statistics and ethics in medicalresearch.3. How large a sample. BMJ 1980, 281:1336-1338.

4. Relton C, Torgerson D, O'Cathain A, Nicholl J: Rethinking pragmatic randomised controlled trials: introducing the "cohort multiple randomised controlled trial" design. BMJ 2010, 340:c1066.

5. Watson JM, Torgerson DJ: Increasing recruitment to randomised trials: a review of randomised controlled trials. BMC Med Res Methodol 2006, 6:34.

6. Puffer S, Torgerson DJ: Recruitment difficulties in randomised controlled trials. Control Clin Trials 2003, 24:214s-215s.

7. Gates $S$, Brocklehurst P, Campbell M, Elbourne D: Recruitment to multicentre trials. BJOG 2004, 111:3-5.

8. Treweek S, Pitkethly M, Cook J, Kjeldstrom M, Taskila T, Johansen M, Sullivan $F$, Wilson S, Jackson C, Jones R, Mitchell E: Strategies to improve recruitment to randomised controlled trials. Cochrane Database Syst Rev 2010, 1, MR000013.

9. Bauer P, Brannath W: The advantages and disadvantages of adaptive designs for clinical trials. Drug Discov Today 2004, 9:351-357.

10. Schulz KF, Altman DG, Moher D: CONSORT Group: CONSORT: Statement: updated guidelines for reporting parallel group randomised trials. BMJ 2010, 340:c332.

doi:10.1186/1745-6215-14-166

Cite this article as: Sully et al: A reinvestigation of recruitment to randomised, controlled, multicenter trials: a review of trials funded by two UK funding agencies. Trials 2013 14:166.

\section{Submit your next manuscript to BioMed Central and take full advantage of:}

- Convenient online submission

- Thorough peer review

- No space constraints or color figure charges

- Immediate publication on acceptance

- Inclusion in PubMed, CAS, Scopus and Google Scholar

- Research which is freely available for redistribution 